\title{
Alveolar Langerhans Cell Histiocytosis - A Case Report
}

\author{
Atri R, Dhankhar R, Dhull AK, Nair VJ, Kaushal V
}

\section{ABSTRACT}

Langerhans cell histiocytosis is a rare disorder, usually occurring in children and young adults. A five year old male child presented with ulcers in lower left alveolar ridge with mobility of adjacent teeth of four months duration. After all relevant radiological and histopathological investigations final diagnosis of multicentric langerhans cell histiocytosis stage - II was made. The patient was put on chemotherapy with CHOP (Cyclophosphamide, Adriamycin, Vincristine and Prednisolone) regimen three weekly for eight courses. Now after six months of cessation of chemotherapy, the patient is in complete clinical remission.

\section{Contact Author}

Dr. Rajeev Atri

E-mail : rajeevatri@gmail.com

\section{KEYWORDS: Langerhans Cell Histioctosis, Alveolar, Chemotherapy.}

\section{L} angerhans cell histiocytosis is a rare disorder, usually occurring in children and young adults, with no bias for race, but with males being affected more frequently than females and is characterized by the idiopathic proliferation of Langerhans cells or their marrow precursors. The term embraces the whole clinical spectrum of the disorder from single bone lesions to an aggressive widespread multisystem disease. We report a case of multicentric langerhans cell histiocytosis involving alveolar bone in relation to deciduous molars in all four quadrants and a lytic lesion involving left side of mandible.

\section{Case Report}

A five year old male child presented with ulcers in lower left alveolar ridge with mobility of adjacent teeth of four months duration. Patient was treated symptomatically by private practitioner. The patient did not get any relief and teeth mobility further increased. Then the patient was referred to our institute. On examination mobility of deciduous molars in all four quadrants along with ulcerated lesion in bilateral retro molar area were detected. X-ray and CT scan revealed alveolar bone destruction in relation to deciduous molars in all four quadrants and a lytic lesion involving left side of mandible (Fig. 1,2). No associated soft tissue mass was seen. Histopathology revealed Langerhan cell histiocytosis. The final diagnosis of multicentric langerhans cell histiocytosis stage - II was made. The patient was put on chemotherapy with CHOP (Cyclophosphamide, Adriamycin, Vincristine and Prednisolone) regimen three weekly for eight courses. The patient is in complete clinical remission at present after six months of cessation of chemotherapy.

\section{Discussion}

Langerhans cell histiocytosis is an uncommon disease characterized by abnormal proliferation of langerhans cells in different organs and tissues. Head and neck involvement presents a difficult management challenge. Historically, Lichtenstein and Jaffe, in 1940, first described eosinophilic granuloma(1). Subsequently, Lichtenstein proposed that eosinophilic granuloma, Hand-Schuller- Christian, and Letterer- Siwe disease represent manifestations of a single entity, termed as Histiocytosis X(2). Feldmann et al, in 1985, used the term Langerhans cell histiocytosis ( $\mathrm{LCH})$ to encompass the entities formerly called Histiocytosis X.

Eden, in 1998, staged LCH as follows: Stage I, single lytic bone lesion; Stage II multiple lytic bone lesions (both formerly termed as eosinophilic granulomata); Stage IIIA, bone plus soft tissue lesions, often associated with diabetes insipidus (pituitary involvement) or exophthalmos (previously termed Hand-Schuller-Christian triad); Stage IIIB, soft tissue only, disseminated form (previously termed Letterer-Siwe disease)(3). Our patient belongs to stage II Langerhans cell histiocytosis.

Langerhans' cells are part of the mononuclear phagocytic system. Despite ambivalence regarding the neoplastic or immuno-dysregulartory pathogenesis of $\mathrm{LCH}$, increasing 


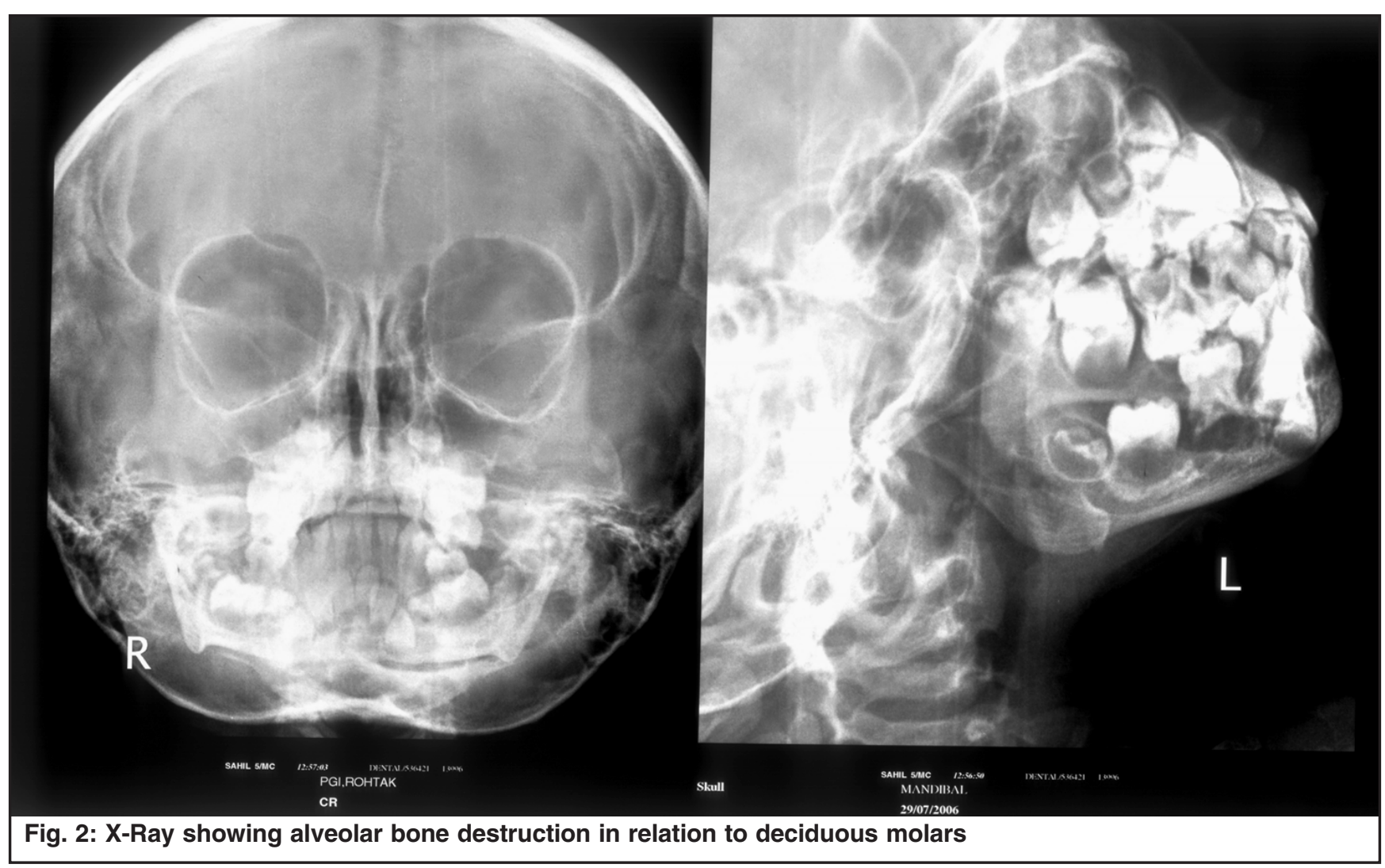

evidence suggests the role of immune abnormality resulting in abnormal proliferation of histiocytes. The diagnosis of $\mathrm{LCH}$ should be suspected when a child or young adult presents with a short history of painful localized swelling and radiographic evidence of bone destruction. LCH can affect many different organs with bone, lymph node and skin lesions most frequently seen(4). CT scans and roentgenographic studies characteristically show circumscribed lytic bony lesions without surrounding sclerosis. When ever LCH is suspected all haematological investigations should be done(4). Surgical exploration and biopsy are essential in diagnosis(4). Histopathologic diagnosis may be established through histochemical analysis or electron microscopy. Histochemical analysis may show positive cells for HLA-DR, S-100 protein, PNA and CD1a. Electron microscopy identifies the presence of cytoplasmic granules, called Birbeck granules, which possess tennis-racket morphology with transverse striations and are thought to be specific markers of Langerhans cells.

The most common presentation in mouth is with periodontal involvement affecting the lower molar areas(5). Premature eruption of teeth or destruction of alveolar ridge, with infiltration of gums with LCH cells, usually results in teeth floating free from their sockets(5). Our patient developed loosening of deciduous molars in all four quadrants during natural history of the disease. Diabetes insipidus is commonest endocrine problem with multi-system disease ranging from 22$50 \%(6)$. It was not present in our patient.
The treatment depends on the extent and severity of disease. When lesions are large or locally invasive, treatment by curettage, low dose radiation therapy, or steroid injection is effective. Disseminated and multifocal $\mathrm{LCH}$ can be successfully treated with chemotherapy and thymus extraction(7). As early as 1940, Otani and Ehrlich observed

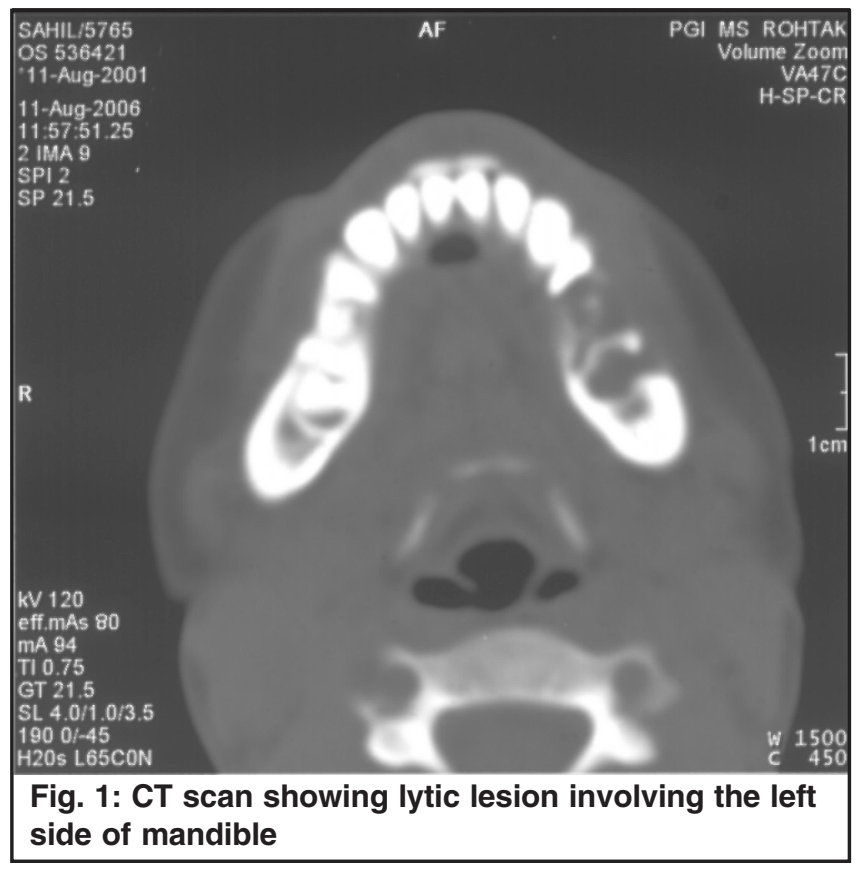


that postoperative radiation therapy may not be necessary(8). Current therapeutic approaches are in favor of a wait and see policy or chemotherapy instead of aggressive local treatments including surgery or radiotherapy. The various chemotherapeutic regimes, which have shown about $50-70 \%$ response in this disease, include vinca alkaloids, doxorubicin, corticosteroids, etoposide and interferons either alone or in combination(9). Single agent etoposide may be better than other drugs(10). However, Cline recommended that LCH should be treated with CHOP chemotherapy(11). In our patient when multifocal disease developed, chemotherapy with $\mathrm{CHOP}$ regimen (cyclophosphamide, adriamycin, vincristine and prednisolone combination) was given and achieved complete response and lasting remission. Regardless of how LCH is treated it is imperative that the patient should be followed carefully for signs of local recurrence or dissemination of disease. The present case highlights the rare presentation of Langerhans cell histiocytosis in a child with alveolar bone destruction in relation to deciduous molars in all four quadrants and a lytic lesion involving left side of mandible. The case emphasizes the importance of a multidisciplinary approach, to the individual oncological patient, in order to achieve, the best possible functional and cosmetic results.

\section{THE AUTHORS}

\section{Dr. Rajeev Atri}

(MD)

Assistant Professor

Department of Radiotherapy,

Regional Cancer Centre,

PGIMS Rohtak, Haryana [India].

\section{Dr . Rakesh Dhankhar}

(MD)

Assistant Professor

Department of Radiotherapy,

Regional Cancer Centre,

PGIMS Rohtak, Haryana [India].

\section{Dr. Anil Kumar Dhull}

(MBBS)

Junior Resident

Department of Radiotherapy,

Regional Cancer Centre, PGIMS Rohtak, Haryana [India].

\section{Dr. Vimoj Nair}

(MBBS)

Junior Resident

Department of Radiotherapy,

Regional Cancer Centre, PGIMS Rohtak, Haryana [India].

\section{Dr. Vivek Kaushal}

(MD, DNB)

Senior Professor and Head

Department of Radiotherapy,

Regional Cancer Centre, PGIMS Rohtak, Haryana [India].

\section{References}

1. Lichtenstein L, Jaffe HL. Eosinophilic granuloma of bone with a report of a case. Am J Pathol 1940;16:595-604.

2. Lichtenstein L. Integration of eosinophilic granuloma of bone, Letterer-Siwe-disease \& Schuller-Christian disease as related manifestations of a single nosologic entity. Arch Pathol 1953;56: 84-102.

3. Eden OB. Oncology and terminal care. In: Campbell AGM McIntosh N, eds. Forfar and ArNeil's:Textbook of Pediatrics. New York: Churchill Livingstone 1998; 884-934.

4. Rivera LR, Martinez GG, Altaminaro AE, et al. Langerhans cell histiocytosis: clinical experience with 124 patients. Pediatr Dermatol 1988;5:145-50.

5. Artzi Z, Grosky M, Raviv M. Periodontal manifestations of adult onset histiocytosis. J Periodontol 1989;60:57-66.

6. Sims DG, Histiocytosis X. Follow up of 43 cases. Arch Dis Child 1977;52:433-40.

7. Gross FJ, Waxman JS, Rosenblatt MA, Tabibzadeh SS, Solodnik P. Eosinophilic granuloma of the cavernous sinus and orbital apex in an HIV-positive patient. Ophthalmology 1989;96(4): 462-67.

8. Otani S, Ehrlich JC. Solitary granuloma of bone simulating primary neoplasm. Am J Pathol 1940;16:479-90.

9. Chu AC. Histiocytosis. In: Champion RH, Burton JL, Burns DA Beathnach SM, eds. Textbook of Dermatology. Oxford: Blackwell Science Ltd, 1998; 2311-36.

10. Broadbent V, Pritchard J, Yeoman E: Etoposide (VP-16) in the treatment of mutisystem Langerhans histiocytosis. Med Pediatr Oncol 1989;17: 97-100.

11. Cline MJ. Histiocytic malignancies. In: Haskell CM, Berek JS, eds. Cancer treatment. Philadelphia: WB Saunders Company, 1995;943-50. 